\title{
Stereochemical Influence of the Ligand on the Structure of Manganese Complexes; Implications for Catalytic Epoxidations
}

\author{
Meenal D. Godbole, ${ }^{\dagger}$ Anna C.G. Hotze, ${ }^{+}$Ronald Hage, ${ }^{\#}$ Allison M. Mills, ${ }^{\star}$ Huub Kooijman, \\ Anthony L. Spek, and Elisabeth Bouwman, *
}

Table of hydrogen bonding interactions in complexes R-2, R-4 and RS-5.

Table of electrochemical data for the complexes R-1, R-2, RS-1, RS-3, R-4 and RS-5.

ESI-MS spectrum of the complex R-4 in MeOH (positive mode); inset showing the calculated isotope pattern.

ESI-MS spectrum of the complex R-4 in MeOH (negative mode) ; inset showing the calculated isotope pattern.

ESI-MS spectrum of the complex RS-5 in acetone (positive mode) ; inset showing the calculated isotope pattern.

ESI-MS spectrum of the complex RS-5 in acetone (negative mode) ; inset showing the calculated isotope pattern.

Cyclic voltammogram of the complex R-1 at scan rate $0.2 \mathrm{~V}$ in an EtOH/Acetonitrile mixture.

Cyclic voltammogram of RS-1 at a scan rate of $0.2 \mathrm{~V} / \mathrm{s}$ in an EtOH/Acetonitrile mixture.

Cyclic voltammogram of complex RS-3 at a scan rate of $0.2 \mathrm{~V} / \mathrm{s}$ in an EtOH/Acetonitrile mixture.

Cyclic voltammogram of complex R-2 at a scan rate of $0.2 \mathrm{~V} / \mathrm{s}$ in an EtOH/Acetonitrile mixture.

Cyclic voltammogram of complex R-4 at a scan rate of $0.2 \mathrm{~V} / \mathrm{s}$ in an EtOH/Acetonitrile mixture.

Cyclic voltammogram of complex RS-5 at a scan rate of $0.2 \mathrm{~V} / \mathrm{s}$ in an EtOH/Acetonitrile mixture.

Inversion recovery pulse sequence for the complex RS-5.

ESI-MS spectrum of a mixture of $R-\mathrm{HphoxCOOCH}_{3}, S-\mathrm{HphoxCOOCD}_{3}$, and $\mathrm{Mn}(\mathrm{II})$ perchlorate in $1: 1: 1$ ratio. 
Table S1: Hydrogen bonding interactions in complexes R-2, R-4 and RS-5.

\begin{tabular}{|c|c|c|c|c|c|}
\hline \multicolumn{6}{|c|}{$\mathbf{R}-2$} \\
\hline Donor - H....Acceptor & [ARU] & D-H & H...A & D...A & $\mathrm{D}-\mathrm{H} \ldots \mathrm{A}$ \\
\hline $\mathrm{O}(6 \mathrm{~A})-\mathrm{H}(6 \mathrm{~A}) \mathrm{O}(47)$ & & 0.84 & 1.98 & $2.813(4)$ & 174 \\
\hline \multicolumn{6}{|c|}{$\mathrm{R}-4^{\mathrm{a}}$} \\
\hline $\mathrm{N}(92)-\mathrm{H}(92 \mathrm{~A}) \ldots \mathrm{O}(27)$ & {$[4555.01]$} & 0.92 & 1.93 & $2.854(3)$ & 177 \\
\hline $\mathrm{N}(92)-\mathrm{H}(92 \mathrm{~A}) \ldots \mathrm{O}(28)$ & {$[4555.01]$} & 0.92 & 2.59 & $3.215(3)$ & 125 \\
\hline $\mathrm{N}(92)-\mathrm{H}(92 \mathrm{~B}) \ldots \mathrm{O}(47)$ & {$[4655.01]$} & 0.92 & 1.89 & $2.796(3)$ & 170 \\
\hline $\mathrm{N}(97 \mathrm{~A})-\mathrm{H}(97 \mathrm{~A}) \ldots \mathrm{O}(87)$ & ] & 0.92 & 1.88 & $2.800(7)$ & 173 \\
\hline $\mathrm{N}(97 \mathrm{~A})-\mathrm{H}(97 \mathrm{~B}) \ldots \mathrm{O}(67)$ & {$[1655.02]$} & 0.92 & 2.00 & $2.917(7)$ & 176 \\
\hline \multicolumn{6}{|c|}{ RS-5 $5^{b}$} \\
\hline $\mathrm{N}(1)-\mathrm{H}(1) \quad \ldots \mathrm{O}(28)$ & ] & 0.93 & 1.92 & $2.798(5)$ & 156 \\
\hline $\mathrm{O}(1)-\mathrm{H}(1 \mathrm{~A}) \ldots \mathrm{O}(28)$ & ] & 0.84 & 1.83 & $2.671(3)$ & 177 \\
\hline $\mathrm{O}(1)-\mathrm{H}(1 \mathrm{~B}) \ldots \mathrm{O}(27)$ & {$[1455.01]$} & 0.81 & 1.94 & $2.694(3)$ & 154 \\
\hline
\end{tabular}

$\mathrm{a}=$ Translation of ARU-code to Equivalent Position Code

$[4555.01]=-\mathrm{x}, 1 / 2+\mathrm{y}, 1 / 2-\mathrm{z},[4655.01]=1-\mathrm{x}, 1 / 2+\mathrm{y}, 1 / 2-\mathrm{z},[1655.02]=1+\mathrm{x}, \mathrm{y}, \mathrm{z}$

$\mathrm{b}=$ Translation of ARU-code to Equivalent Position Code

$[1455.01]=-1+\mathrm{x}, \mathrm{y}, \mathrm{z}$.

Table S2: Electrochemical data for the complexes.

\begin{tabular}{lllllll}
\hline & R-1 & R-2 & RS-1 & RS-3 & R-4 & RS-5 \\
\hline $\mathrm{E}_{1 / 2}(\mathrm{~V})$ & 0.040 & 0.008 & 0.044 & 0.044 & 0.868 & 0.931 \\
$\Delta \mathrm{E}(\mathrm{mV})$ & 181 & 126 & 122.4 & 134 & 131 & 340 \\
$\mathrm{ip}_{\mathrm{a}} / \mathrm{ip} \mathrm{p}_{\mathrm{c}}$ & 0.57 & 0.96 & 0.98 & 0.85 & 1.38 & 0.93 \\
\hline
\end{tabular}




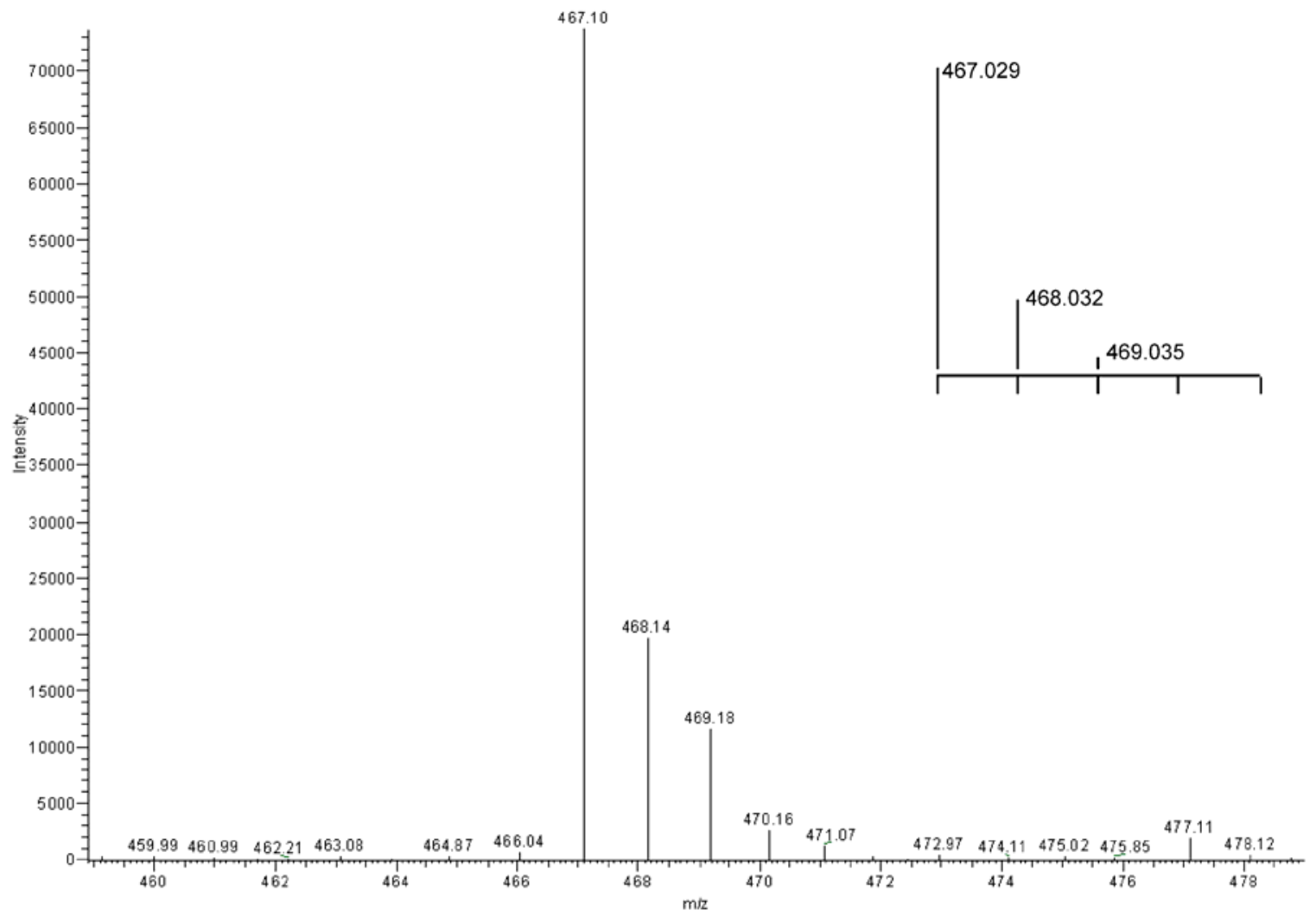

Figure S1: ESI-MS spectrum of the complex R-4 in MeOH (positive mode); inset showing the calculated isotope pattern. 


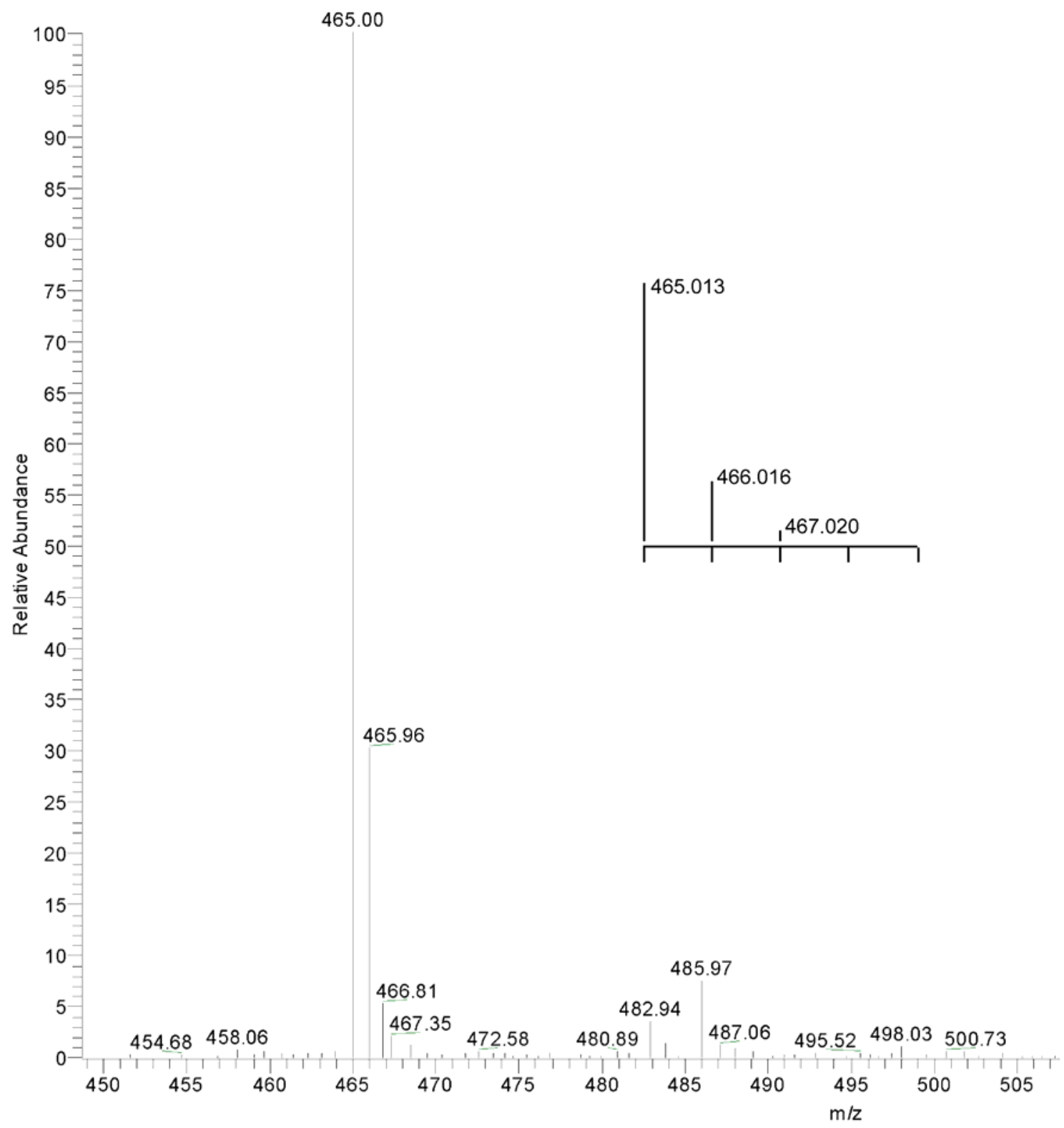

Figure S2: ESI-MS spectrum of the complex R-4 in $\mathrm{MeOH}$ (negative mode) ; inset showing the calculated isotope pattern. 


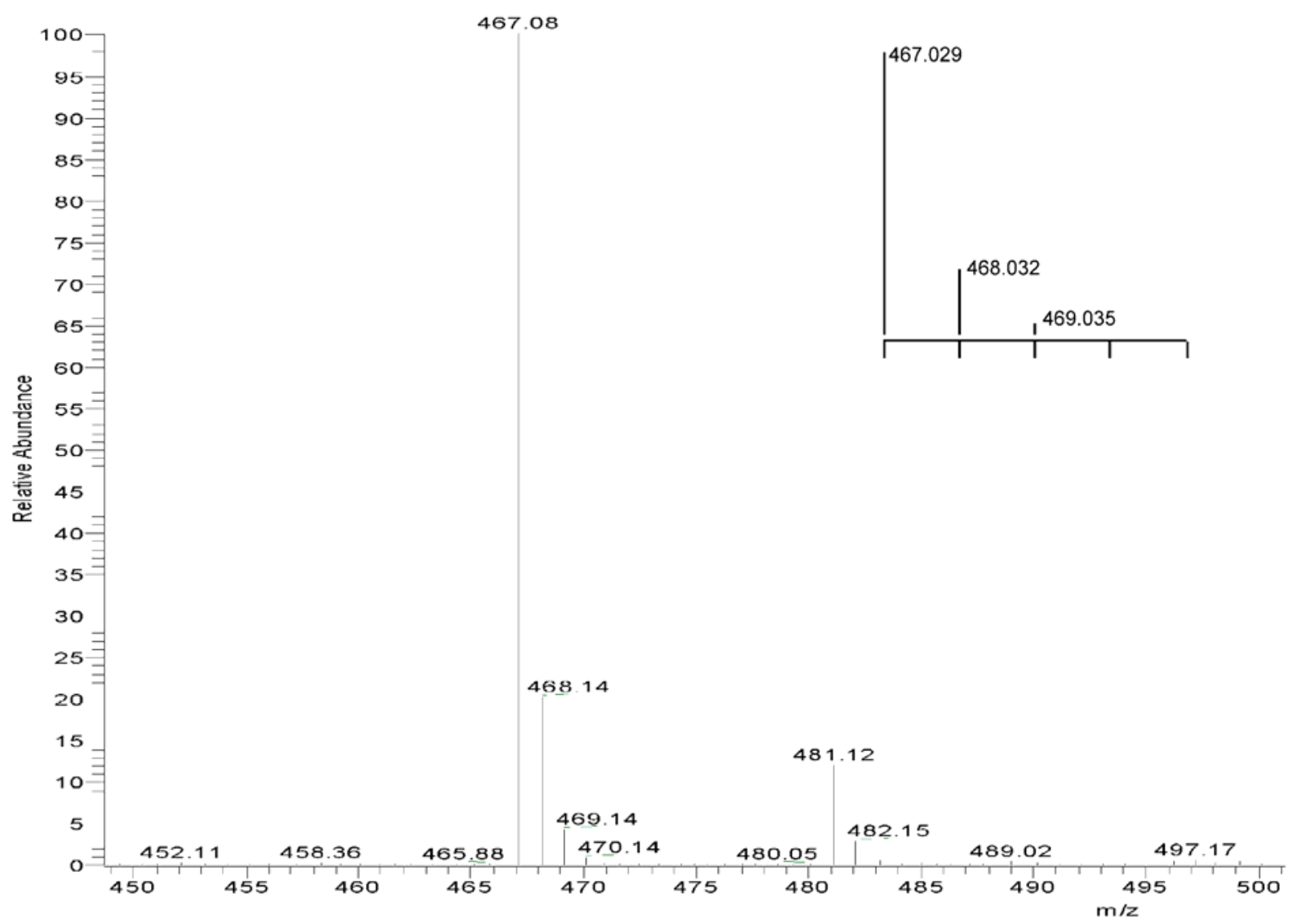

Figure S3: ESI-MS spectrum of the complex RS-5 in acetone (positive mode); inset showing the calculated isotope pattern. 


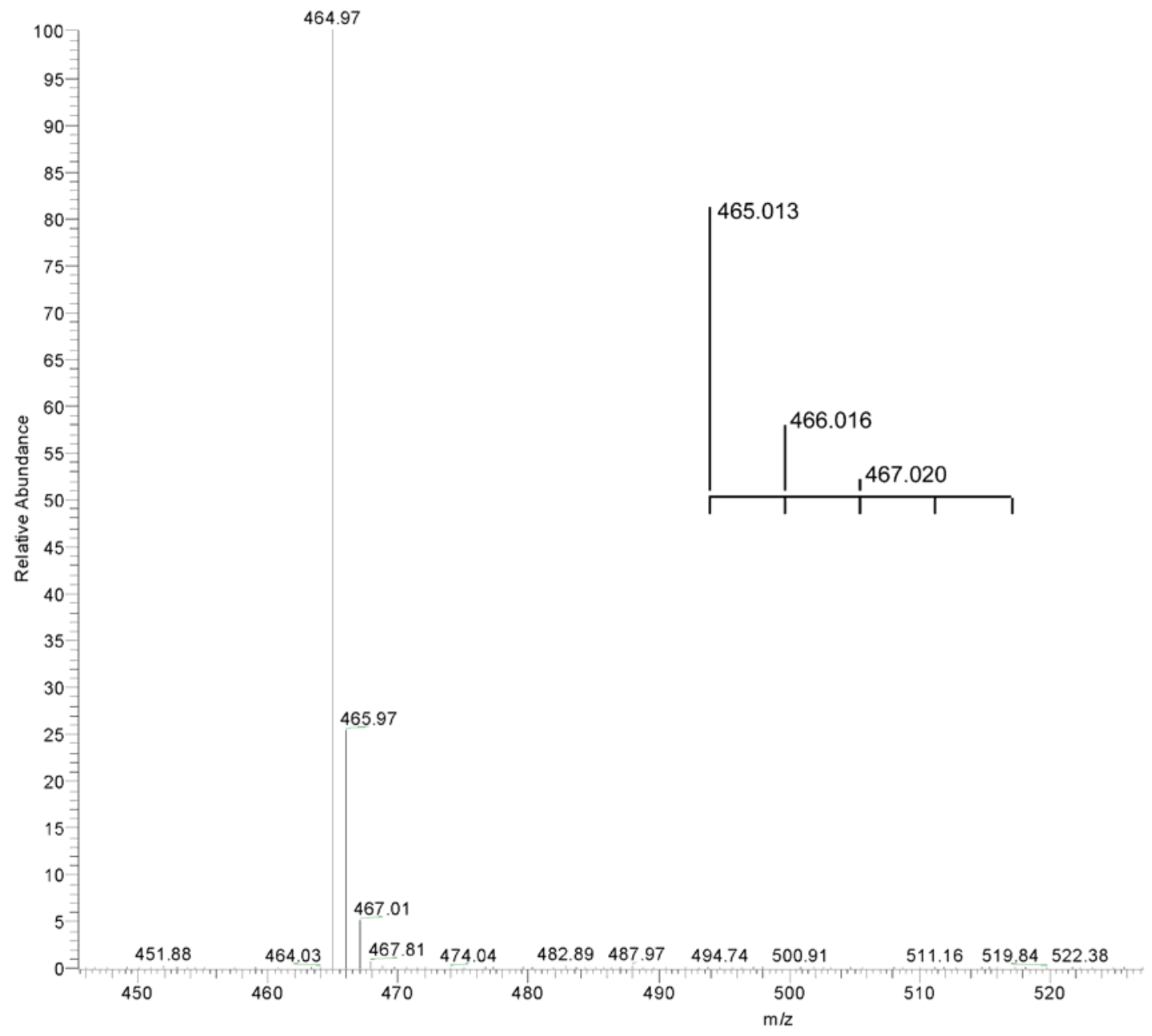

Figure S4: ESI-MS spectrum of the complex RS-5 in acetone (negative mode); inset showing the calculated isotope pattern. 


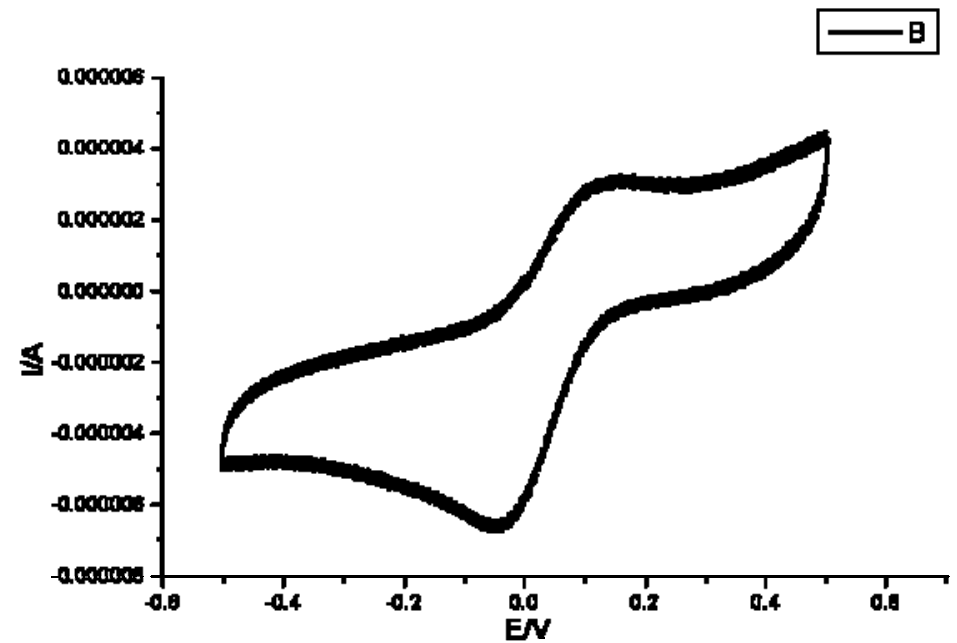

Figure S5: Cyclic voltammogram of the complex R-1 at scan rate $0.2 \mathrm{~V}$ in an EtOH/Acetonitrile mixture.

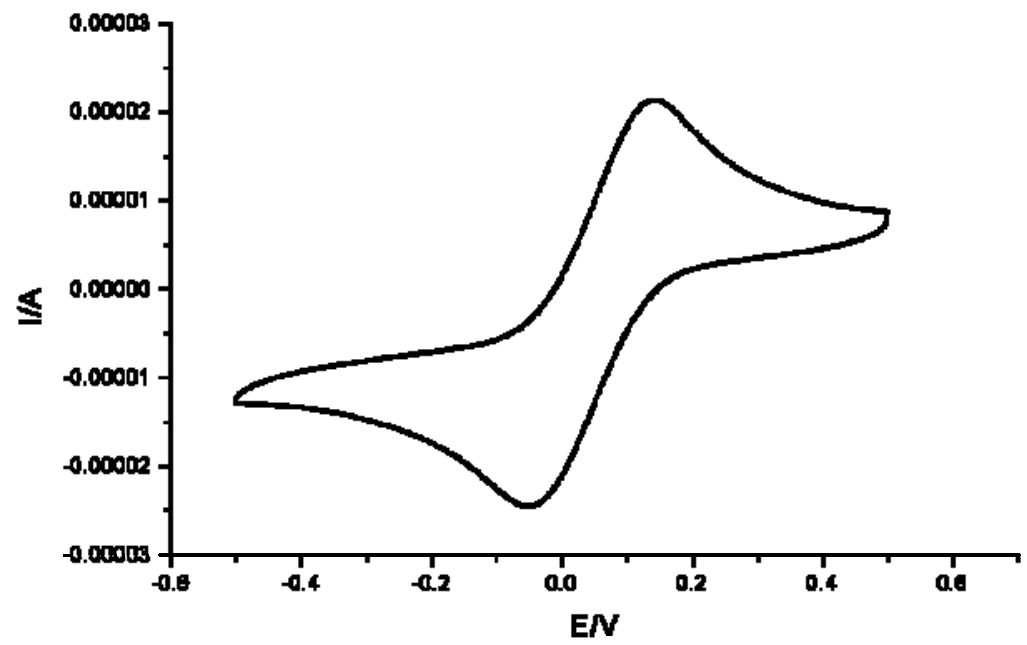

Figure S6: Cyclic voltammogram of the complex RS-1 at scan rate $0.2 \mathrm{~V}$ in an EtOH/Acetonitrile mixture. 


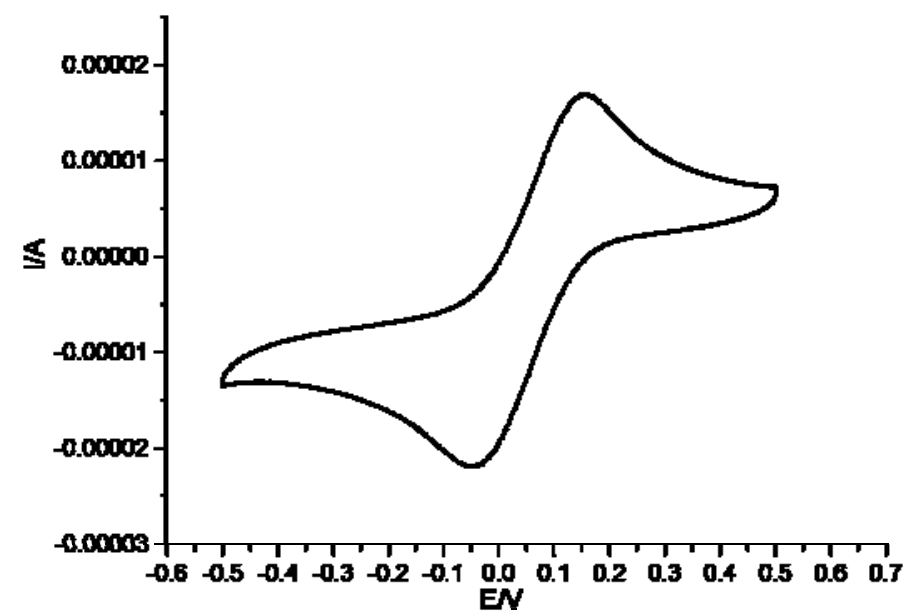

Figure S7: Cyclic voltammogram of complex RS-3 at a scan rate of $0.2 \mathrm{~V} / \mathrm{s}$ in an EtOH/Acetonitrile mixture.

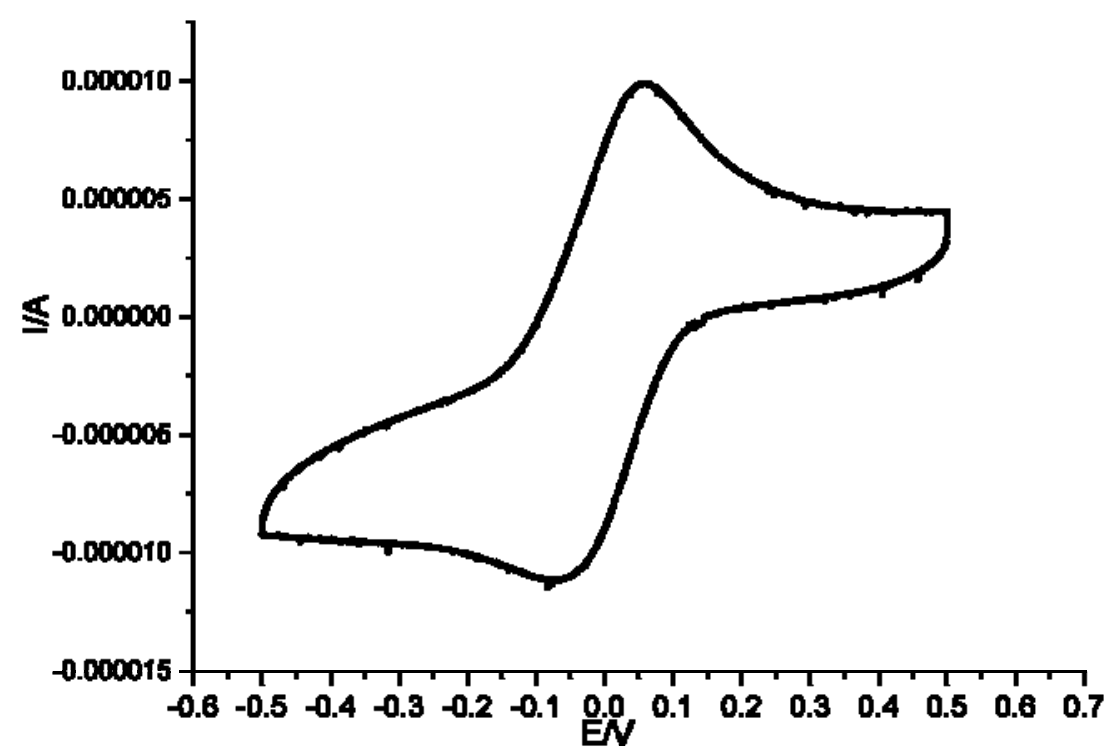

Figure S8: Cyclic voltammogram of R-2 at a scan rate of $0.2 \mathrm{~V} / \mathrm{s}$ in an EtOH/Acetonitrile mixture. 


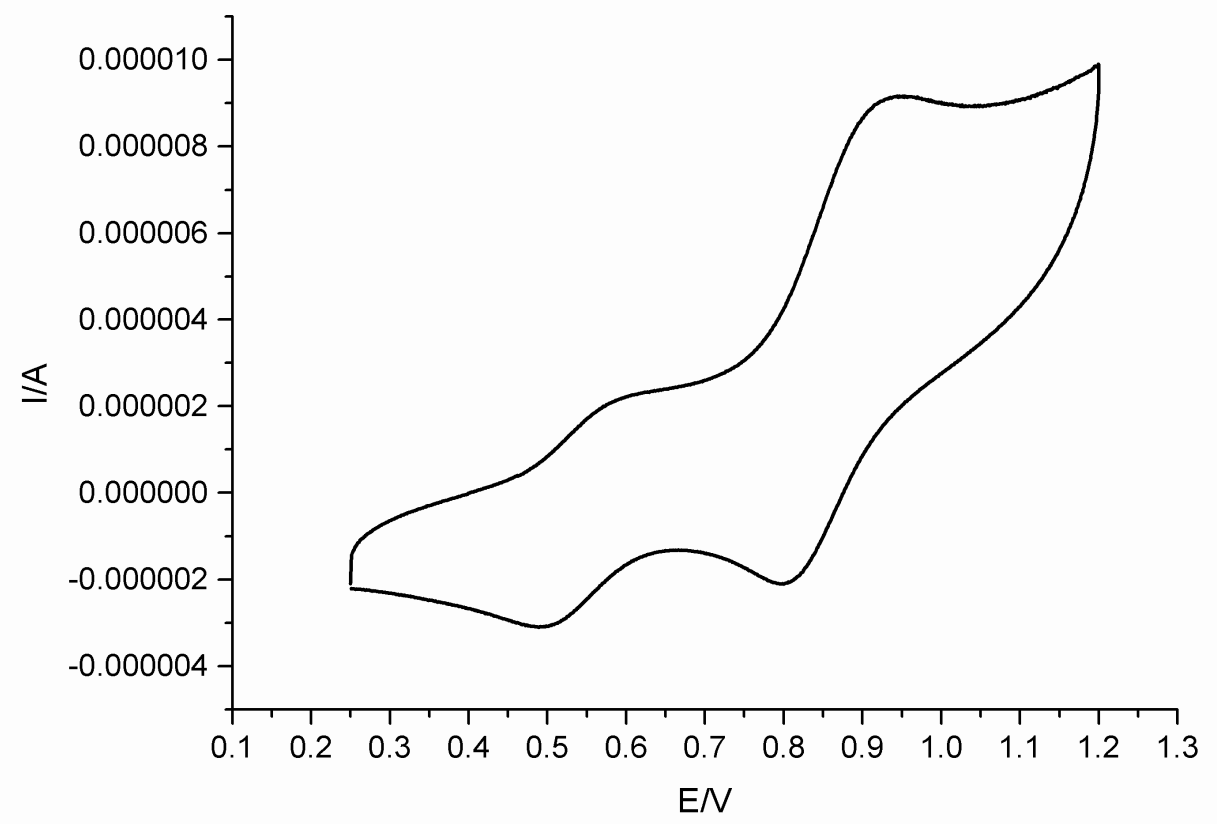

Figure S9: Cyclic voltammogram of R-4 at a scan rate of $0.2 \mathrm{~V} / \mathrm{s}$ in an EtOH/Acetonitrile mixture. 


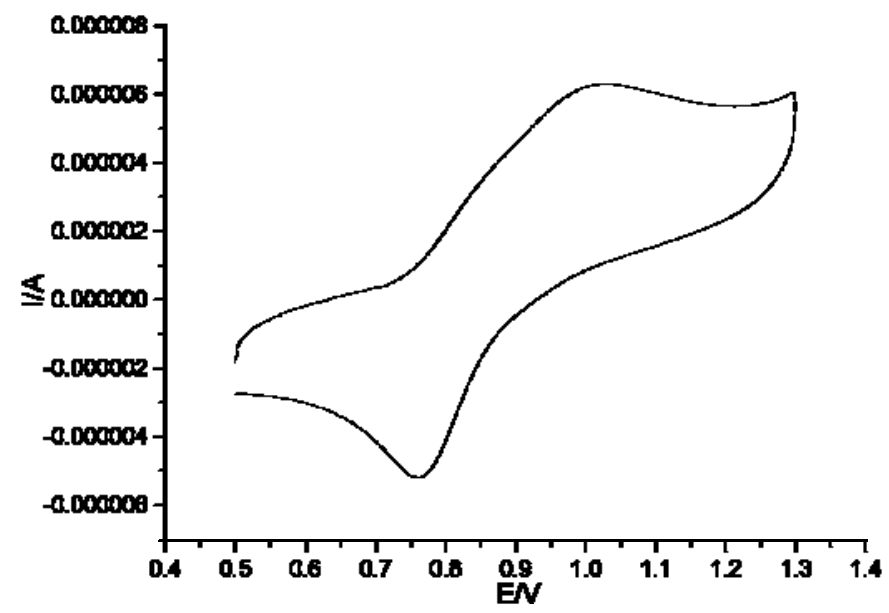

Figure S10: Cyclic voltammogram of RS-5 at a scan rate of $0.2 \mathrm{~V} / \mathrm{s}$ in an EtOH/Acetonitrile mixture. 


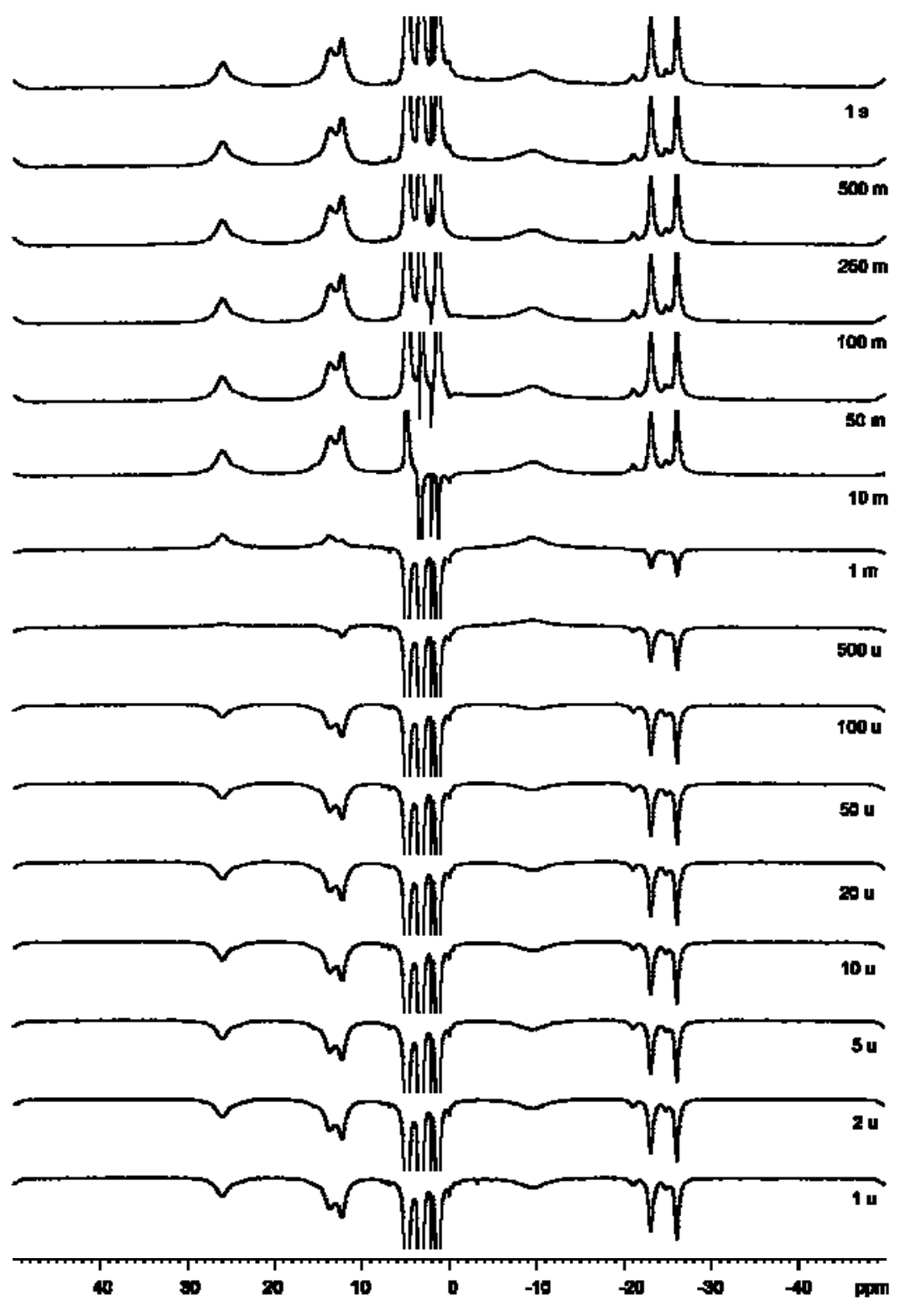

Figure S11: Inversion recovery pulse sequence for the complex RS-5. 


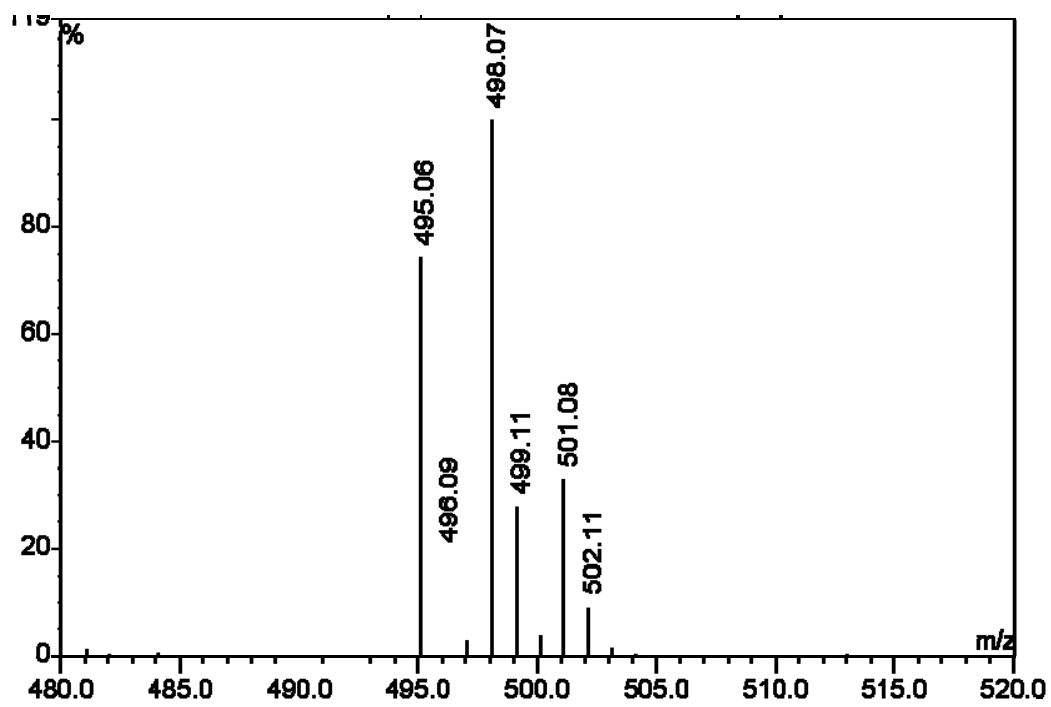

Figure S12: ESI-MS spectrum of a mixture of $R$-HphoxCOOCH$H_{3}, S-H p h o x \mathrm{COOCD}_{3}$, and $\mathrm{Mn}(\mathrm{II})$ perchlorate in 1:1:1 ratio. 